\title{
Riscos ocupacionais na fabricação de medicamentos: análise de uma indústria localizada no Nordeste brasileiro
}

\author{
Occupational risks in the production of \\ medicine: analysis of an industry located \\ in the northeast of Brazil
}

${ }^{1}$ Doutorando em Tecnologia de Processos Químicos e Bioquímicos pela Escola de Química da Universidade Federal do Rio de Janeiro (UFRJ), M.Sc. Engenharia Química pela Universidade Federal de Pernambuco (UFPE), engenheiro de Segurança do Trabalho, coordenador de boas práticas de fabricação e assuntos regulatórios e presidente da Comissão Interna de Prevenção de Acidentes (CIPA) do Laboratório Farmacêutico do Estado de Pernambuco S/A - LAFEPE ${ }^{\circledR}$.

\begin{abstract}
Resumo
A fabricação de medicamentos é um processo industrial complexo que exige altos investimentos em pesquisa e desenvolvimento, produção e controle de qualidade dos produtos, aquisição de substâncias, armazenagem e distribuição dos produtos, manutenção de pessoal qualificado e reciclado nos conhecimentos da área. Paradoxalmente, apesar de ser um segmento que agrega tecnologias ultramodernas e do grande suporte proporcionado pelas Boas Práticas de Fabricação (BPF) de medicamentos fixados pela legislação sanitária, a indústria de medicamentos convive com diversos riscos ambientais, aqui incluídos os riscos ao consumidor, à saúde dos seus trabalhadores e os associados ao meio ambiente. O objetivo deste trabalho é apresentar o resultado da identificação dos riscos ocupacionais de uma indústria farmacêutica pública localizada no nordeste do Brasil, obtido através das investigações e avaliações realizadas pela Comissão Interna de Prevenção de Acidentes (CIPA) da empresa, e contribuir para a realização de estudos avançados relacionados com saúde e doença dos trabalhadores na indústria farmacêutica de medicamentos.
\end{abstract}

Palavras-chaves: riscos ocupacionais, fabricação de medicamentos, Boas Práticas de Fabricação (BPF), indústria farmacêutica.

\begin{abstract}
The production of medicine is a complex industrial process that demands high investments not only in research and development, but also in production and quality control, in acquiring chemicals, in storage and distribution, and in keeping staff qualified and updated. Paradoxically, in spite of being a segment that deals with ultra modern technology, and the support provided by the good manufacturing practices (GMP) requirements foreseen by the sanitary legislation, the drug industry runs several environmental risks, including their consumers' and workers' health hazards as well as the environment around their plants. This study aims at presenting the results of a research on occupational hazards developed by the company's Internal Commission for the Prevention of Accidents (CIPA) in a governmental pharmaceutical industry located in the northeast of Brazil. I hope it will contribute to stimulate other advanced studies related to workers' health and illness in the pharmaceutical industry.
\end{abstract}

Keywords: occupational risks, production of medicine, good manufacturing practices (GMP), pharmaceutical industry. 


\section{Introdução}

Ao contrário das indústrias de transformação tradicionais, a indústria farmacêutica tem sua atividade extremamente regulada pelo poder público. Neste processo, nenhum dos produtos sujeitos aos regimes de vigilância sanitária, tais como medicamentos, insumos farmacêuticos, drogas, correlatos, cosméticos, produtos de higiene, perfumes e similares, saneantes domissanitários, produtos destinados à correção estética, poderão ser extraídos, produzidos, fabricados, embalados ou reembalados, importados, exportados, armazenados ou expedidos antes da concessão do registro do produto junto ao poder público regulador.

À concessão deste registro ficam vinculadas todas as especificações de insumos a serem usados na fabricação, o conhecimento sobre os fornecedores desses insumos, a apresentação das formulações nas composições unitárias, a definição dos processos e do local de fabricação, o tamanho dos lotes a serem produzidos, todas as análises realizadas pelo controle de qualidade dos insumos e produtos acabados, a fixação das formas de apresentação ao consumidor, a apresentação dos testes de eficácia terapêutica, a rotulagem dos produtos bem como as informações técnicas que serão disponibilizadas aos pacientes e prescritores nas bulas, não cabendo nenhuma alteração das condições originais nas quais foi concedido o registro por parte da indústria sem a manifestação favorável do órgão regulador.

Além das exigências para concessão do registro, a fabricação de medicamentos está cercada de uma série de práticas e controles que visam a assegurar que os produtos são consistentemente produzidos e controlados, com padrões de qualidade apropriados para o uso pretendido e requerido pelo registro. São as Boas Práticas de Fabricação (BPF) para a indústria de medicamentos, recentemente instituídas no Brasil. O cumprimento das BPF está dirigido primeiramente para a diminuição dos riscos inerentes a qualquer produção farmacêutica, os quais não podem ser detectados através da realização de ensaios nos produtos acabados. Os riscos são constituídos essencialmente por: contaminação-cruzada, contaminação por partículas e troca ou mistura de produto (BRASIL, 2003).

Dentre outros requisitos, as BPF determinam que todos os processos de fa- bricação sejam claramente definidos e sistematicamente revisados em função da experiência adquirida, que sejam definidas as etapas críticas dos processos de fabricação, que o pessoal envolvido na fabricação e o produtor possuam infra-estrutura necessária, a qual deve incluir: pessoal qualificado e devidamente treinado, espaço e instalações adequadas, equipamento e serviços adequados, materiais, recipientes e rótulos corretos, procedimentos e instruções aprovadas, armazenamento e transporte adequados para controle em processo (BRASIL, 2003).

Esta nova forma de trabalho instituída pelas BPF procura minimizar os riscos inerentes a cada etapa da fabricação de um medicamento e garantir a eficácia e a segurança terapêutica desejadas para o produto final. Por outro lado, não resta dúvida de que a implementação das BPF na indústria de medicamentos proporcionou um grande impacto na saúde dos seus trabalhadores, uma vez que a preservação da qualidade do produto está diretamente ligada a adequadas condições de fabricação e de trabalho, tanto do ponto de vista da infra-estrutura, como de qualificação da mão-de-obra envolvida e de utilização de tecnologias dos processos cuja intervenção do homem se dá de forma segura e confiável.

O processo industrial farmacêutico é complexo, vinculando-se às políticas industrial, científica, tecnológica e de saúde. É um processo que exige investimentos em pesquisa e desenvolvimento, produção e controle de qualidade dos produtos, aquisição de substâncias, armazenagem e distribuição dos produtos e manutenção de pessoal qualificado. Paradoxalmente, apesar de ser um segmento que agrega tecnologias ultramodernas, a indústria de medicamentos convive com diversos riscos ambientais, aqui incluídos aqueles ao consumidor, à saúde dos trabalhadores e ao meio ambiente que cerca os seus ambientes industriais.

Um dos objetivos da vigilância à saúde do trabalhador é conhecer a realidade de saúde da população trabalhadora e proceder a uma avaliação dos processos, dos ambientes e das condições em que o trabalho se realiza, identificando os riscos e as cargas de trabalho a que estão sujeitos os trabalhadores. Em tempos em que se é tão comum o termo boas práticas de fabricação 
na indústria farmacêutica, entendemos que não se pode falar em BPF se o interesse por condições de trabalho saudáveis e seguras não possuir o mesmo grau de importância que o produto final em si.

Muito pouco se estudou, no Brasil, sobre a relação entre a saúde e a doença na indústria de medicamentos. Alguns estudos foram iniciados na Bahia (REGO et al., 1993) e outros integram linhas de pesquisa da Fundação Osvaldo Cruz, no Rio de Janeiro, desde 1997. O objetivo deste trabalho é apresentar o resultado da identificação dos riscos ocupacionais do Laboratório Farmacêutico do Estado de Pernambuco S/A - LAFEPE ${ }^{\circledR}$ (Recife-PE, Brasil) -, uma indústria farmacêutica pública, que, ao longo do tempo, vem aperfeiçoando seus processos e passou a reconhecer o potencial de agravos à saúde dos seus trabalhadores resultantes dos seus processos de fabricação. Este trabalho foi resultado de dois anos (2003 2005) de investigações e avaliações realizadas pela Comissão Interna de Prevenção de Acidentes (CIPA) da empresa. Trata-se de um retrato da percepção dos trabalhadores dos riscos a que estão expostos em diversas linhas de produção e em diversos setores auxiliares e essenciais a uma indústria desta natureza. O trabalho visa a contribuir para a realização de estudos mais aprofundados que estejam relacionados com saúde e doença dos trabalhadores na indústria de medicamentos e foi fonte principal para a elaboração do mapa de riscos ambientais da empresa estudada.

\section{Revisão da Literatura}

Ramazini (1992) dizia, já no século XVIII, que, tendo interrogado os operários de farmácias se adoeceram alguma vez enquanto preparavam remédios, responderam que:

(...) amiúde se sentiram gravemente afetados sobretudo durante a elaboração de láudano opiáceo ou pulverizando cantáridas para vesicatórios e outras substâncias venenosas, por causa de suas partículas desprendidas, que, enquanto as esmagam, penetram pelas vias do corpo (...)

Constatava-se que a exposição a substâncias químicas ativas utilizadas no processo de fabricação de medicamentos possuía um potencial nocivo à saúde, realidade que se mantém até hoje, tendo em vista que muitos dos efeitos adversos e riscos associados às drogas somente são percebidos depois de muitos anos de consumo ou exposição, o que enseja riscos não percebidos ou não detectados durante o processo de desenvolvimento dos medicamentos.

As matérias-primas utilizadas na produção de medicamentos raramente podem ser administradas tal como se apresentam, sendo necessário submetê-las, quase sempre, a um certo número de manipulações destinadas a transformá-las nas formas farmacêuticas. Estas representam o produto final nos quais as substâncias ativas são administradas aos doentes. Nas suas atividades, os trabalhadores da indústria farmacêutica podem absorver fármacos não por sua vontade expressa ou por necessidade terapêutica. Os efeitos que derivam desta absorção devem ser considerados potencialmente tóxicos. Esta absorção pode também aumentar os riscos de acidentes, como, por exemplo, por exposição a drogas que induzem a sonolência em indivíduos que trabalham com máquinas em movimento. A exposição crônica a estes compostos poderá resultar, ainda, no desenvolvimento de resistência às drogas, dificultando a eficácia de medicamentos quando, de fato, precisa-se fazer uso destes por ocasião do acometimento de alguma patologia. (ALENCAR, 1999).

As substâncias manuseadas na indústria farmacêutica podem ser de origem vegetal, animal e mineral. Vegetais podem ser tóxicos ou transportar fungos patogênicos e/ou ácaros. Schwartz (1957), citado por Melo (1999), descreveu casos de dermatites causadas por seivas e óleos essenciais de numerosas plantas como mostarda, piretro, raiz de íris, canela, gengibre, citronela, camomila. Enumerou casos de irritação cutânea por alcalóides, tais como estricnina, brucina, atropina, morfina, codeína, cocaína, ópio e quinina. Descreveu também casos de escabiose e outras acaríases de grãos e plantas.

Thomas \& Decoufle (1979) investigaram as causas de mortalidade em trabalhadores de indústrias farmacêuticas num período de 22 anos. Apesar de terem observado vários casos de câncer na população analisada, não chegaram a dados conclusivos. 
Estudo similar foi repetido por Harrington \& Goldblatt (1986), sete anos após, e chegaram a conclusões semelhantes.

Chida \& Uehata (1979) estudaram a exposição de 24 trabalhadores de uma indústria farmacêutica que tinham contato com poeiras de bromelina, tripsina e ácido flufenâmico, agentes antiinflamatórios, florpropion, antiespasmódico, ampicilina, cefalexina e antibióticos. Encontraram casos de asma, irritação das mucosas, incluindo sistema respiratório, reações alérgicas e irritações na pele, que foram associadas à grande variedade de drogas manipuladas por estes trabalhadores e a um controle inadequado desses materiais na forma de pó no processo industrial. Estudo similar foi repetido por Chida (1986), chegando a conclusões semelhantes.

O efeito da exposição ocupacional a uma droga anti-hipertensiva de nome alprenolol foi estudado por Ekenvall \& Forsbeck (1978). Quatorze trabalhadores apresentaram fortes reações alérgicas na pele e nas mucosas.

Estudo realizado por Tomei et al. (1995) investigou a possibilidade de causar hepatoxicidade por exposição a várias substâncias, tais como eritromicina, cortisonas, parabenzoatos, iodo-cloro-oxiquinolina, usadas no processo de fabricação de uma indústria farmacêutica. O estudo concluiu que existe uma forte relação entre a exposição a estes agentes e problemas de fígado nos trabalhadores envolvidos na pesquisa.

Rembadel \& Rudzki (1990) observaram que a exposição a penicilinas, tetraciclinas, dissulfiram e aminofilina podem produzir fortes reações alérgicas ou reações de sensibilidade.

Menon \& Das (1977) relataram um caso de asma após um ano de trabalho na seção de encapsulamento de antibióticos de uma indústria farmacêutica. Os autores associaram esta disfunção à exposição à variedade de agentes químicos, entre os quais a tetraciclina.

A piperacilina sódica foi o agente causador de asma ocupacional em estudo de caso de exposição de um trabalhador a este antibiótico, realizado por Moscato et al. (1975).

Davies \& Pepys (1975) investigaram a ocorrência de sintomas de asma ocupacional apresentados por um trabalhador de uma indústria farmacêutica. Os autores associaram os sintomas à exposição do trabalhador ao antibiótico espiramicina. Malet et al. (1992) estudaram um caso similar. A investigação de asma ocupacional por exposição a espiramicina foi também objeto de estudo elaborado por Malo \& Cartier (1988).

Outros casos de asma em trabalhadores de indústrias farmacêuticas, desta vez associados à exposição à hidralazina, à penicilamina, ao salbutamol e a poeiras resultantes do processo de produção de enzimas, respectivamente, foram reportados por Perrin et al. (1990), Lagier et al. (1989), Agius et al. (1994) e Losada et al. (1992).

A exposição de 11 trabalhadores ocorrida durante o processo de produção do medicamento metotrexato levou Sessink et al. (1994) a detectar, em amostras de urina e de ar expirado, grandes variações de concentração da droga no organismo desses trabalhadores.

Hansson et al. (1980) analisaram o trabalho de mulheres grávidas em laboratórios de indústrias farmacêuticas. Os resultados apontaram casos de má-formações e mortalidades dos fetos e tais observações levaram os autores a concluir que, em períodos de gestação, o trabalho em laboratórios químicos representa um risco à saúde do feto.

Karpenko, citado por Rego et al. (1993), demonstrou alta correlação entre a incidência de doenças alérgicas do trato respiratório e da pele e a concentração de ampicilina no ar.

Martindale (1997) e Merler et al. (1996) alertaram para o manuseio sem proteção de drogas antineoplásicas que podem causar reações tóxicas e/ou alérgicas, além do risco potencial de carcinogenicidade.

Pushpavathi et al. (1986) referiram que é de grande importância e requer estudos mais profundos a possibilidade de aparecimento de câncer ou efeitos genéticos devidos à exposição a fármacos.

Rêgo et al. (1993) desenvolveram um dos raros estudos publicados no Brasil sobre os principais sintomas referidos por trabalhadores de uma indústria farmacêutica produtora de medicamentos localizada na Bahia, no nordeste brasileiro (vide Tabela 1).

No estudo, os autores observaram uma variada gama de sintomas, chamando a atenção o cansaço físico, a dor nas costas, a cefaléia, o nervosismo e a dor nos membros inferiores ( $>50 \%$ ), porém, segundo os autores, não se pôde estabelecer uma relação 
de causa e efeito com os riscos ocupacionais tendo em vista que alguns sintomas poderiam ser decorrentes das condições de vida em geral, como nível salarial, local de moradia, características do domicílio, alimentação, lazer etc. Das queixas apresentadas na Tabela 1, destacam-se ainda o prurido nos olhos e a obstrução nasal como aqueles mais diretamente ligados a condições de trabalho.

Tabela 1 Principais sintomas referidos por trabalhadores de uma indústria farmacêutica (Rego et al., 1993)

\begin{tabular}{lll}
\hline \multicolumn{1}{c}{ Sintomas apresentados } & $n^{*}$ & $\%$ \\
\hline Cansaço físico & 60 & 55,6 \\
Dor nas costas & 58 & 53,7 \\
Cefaléia & 56 & 51,9 \\
Nervosismo & 54 & 50,0 \\
Dor nos membros inferiores & 54 & 50,0 \\
Esquecimento & 44 & 40,7 \\
Cansaço mental & 43 & 39,8 \\
Coceira nos olhos & 43 & 39,8 \\
Fraqueza muscular & 38 & 35,2 \\
Tontura & 35 & 32,4 \\
Dor nos membros superiores & 33 & 30,6 \\
Obstrução nasal & 32 & 29,6 \\
Insônia & 30 & 27,8 \\
Tosse & 30 & 27,8 \\
\hline
\end{tabular}

* número de trabalhadores.

O controle da exposição a agentes químicos nos ambientes de trabalho é assunto previsto na legislação brasileira, que estabelece, dentre outros parâmetros, os limites de tolerância (em inglês, Threshold Limit Values - TLV) para exposição a agentes químicos para uma jornada de trabalho de 8 horas diárias. Estes estão, em sua maioria, desatualizados e incluem um número reduzido de agentes quando comparados com o número de substâncias utilizadas nos mais variados processos industriais. Mesmo podendo lançar mão de outras legislações, ainda assim o vazio é enorme. É um número gigante quando comparado à quantidade de produtos químicos que já tiveram seus limites de tolerância estabelecidos alguma vez. Dentro desta categoria de substâncias químicas que não possuem limites de tolerância, estão os fármacos, que podem ser vistos como inofensivos por serem considerados substâncias que curam, mas que, na verdade, podem trazer prejuízos à saúde dos trabalhadores.

Um dos principais desafios para os higienistas industriais na indústria farmacêutica é a produção de poeiras no manu- seio de sólidos. As operações de moagem, peneiramento, granulação, descarregamento de matérias-primas em sacos e/ou barricas são típicas da alta produção de poeiras (NAUMANNN \& SARGENT, 1997). A American Conference of Governmental Industrial Hygienists (ACGIH), conforme Sargent \& Kirk (1988), generalizou e estabeleceu o limite de $10 \mathrm{mg} / \mathrm{m}^{3}$ para poeiras totais e $5 \mathrm{mg} / \mathrm{m}^{3}$ para poeiras respiráveis de quaisquer compostos que não possuam TLV's. Muitos princípios ativos, porém, produzem resposta farmacológica em concentrações muito inferiores a estes limites. Tal afirmação é feita com base no resultado dos trabalhos de Sargent \& Kirk (1988) e Naumannn \& Sargent (1997), que obtiveram limites de exposição para 32 fármacos inferiores aos limites genéricos da ACGIH. Os mesmos autores consideram que, à luz da tecnologia disponível, equipamentos de proteção coletiva que envolvam ventilação e exaustão não são suficientes para permitir concentrações de poeiras abaixo dos limites que seriam seguros. Fazem-se necessários também a colocação de barreiras além do devido fornecimento de equipamentos de proteção individual. 
Outra questão relevante na indústria farmacêutica é a dos riscos ergonômicos que geram, para os trabalhadores, sobrecarga física, problemas de posturas e lesões osteomusculares. Estes riscos são detectados principalmente no setor de embalagem, mas podem ser encontrados também nos demais, tais como laboratório, administrativo, almoxarifado etc. Segundo Chavalitsakulchai \& Shahnavaz, citados por Melo (1999), aspectos ergonômicos de medidas preventivas deveriam incluir seleção apropriada e treinamento de profissionais para as diversas atividades, projeto ergonômico do ambiente e considerações ergonômicas na organização do trabalho, tais como variações e interrupções de tarefas e posturas adequadas.

Ainda em relação ao aspecto de postura, Rotgoltz et al. (1992), citados por Melo (1999), observaram que, dentre 208 empregados de uma indústria farmacêutica, 138 referiram dor nas costas. A posição sentada prolongada e o trabalho na embalagem ou no departamento de produção foram associados a esta queixa.

Quanto a acidentes do trabalho, podemos citar o estudo de Rêgo et al. (1993), no

\section{Materiais e Métodos}

A indústria farmacêutica estudada neste trabalho foi o Laboratório Farmacêutico do Estado de Pernambuco S/A - LAFEPE ${ }^{\circledR}$, uma empresa pública, localizada em Recife, no estado de Pernambuco, no nordeste brasileiro. Trata-se de uma indústria fundada em 1965, atualmente certificada em boas práticas de fabricação pela Agência Nacional de Vigilância Sanitária (ANVISA) para suas linhas de sólidos (comprimidos, cápsulas e pós orais), sólidos anti-retrovirais (produtos destinados ao tratamento da AIDS), líquidos não antibióticos (xaropes, soluções, soluções em gotas, suspensões orais) e líquidos antibióticos (suspensões orais). Quanto aos medicamentos produzidos, estes são das mais variadas classes terapêuticas (vide Quadros 1 e 2), além de outros novos ainda em pesquisa e desenvolvimento, como o comprimido do antiparasitário para doença de chagas benznidazol, que está sendo desenvolvido em parceria com o laboratório $\mathrm{ROCHE}^{\circledR}$, e o anti-hipertensivo maleato de enalapril, do antiulcerogênico ranitidina, do antifúngico cetoconazol, do vermífugo albendazol e do antidiabético cloridrato de metfotmina, todos na forma de comprimidos. qual foi observado que mais de um terço dos trabalhadores avaliados referiu já ter sofrido acidentes do trabalho, incluindo acidentes típicos e de trajeto. Segundo os autores, esse valor em si foi bastante elevado e mesmo preocupante, levando-se em conta a baixa média de tempo trabalhado na fábrica.

Destaca-se também a exposição a agentes biológicos (fungos, bactérias e vírus) presentes nos ensaios de controle de qualidade microbiológico, em animais de experimentação que são utilizados no controle de qualidade e na avaliação de eficácia e pesquisa de medicamentos, bem como a agentes físicos, como ruídos resultantes de partes em movimento de máquinas e equipamentos.

Constata-se que há muitas evidências na literatura atestando a presença de uma série de riscos ocupacionais na indústria de medicamentos. Essas reforçam a necessidade de se implementar ações de vigilância em saúde do trabalhador, que passam necessariamente por uma identificação detalhada dos riscos dos processos sem limitar tais ações somente aos critérios previstos nas legislações.

A legislação sanitária exige que cada forma farmacêutica seja produzida em áreas independentes uma da outra, podendo ainda, dentro de cada área, ter separação por classe de produtos. Os produtos líquidos são separados em três linhas: uma para fabricação de xaropes, soluções e suspensões cujo produto final é apresentado na forma de frascos de vidro em volumes que variam de 30 a $200 \mathrm{~mL}$; outra linha, na mesma área, para fabricação de soluções apresentadas em frascos de plásticos gotejadores; e uma outra linha, totalmente independente, destinada a produtos antibióticos. Da mesma forma acontece na fabricação dos medicamentos sólidos. Existem duas unidades produtivas separadas, uma destinada exclusivamente aos produtos sólidos anti-retrovirais, que são produtos classificados como de classes especiais pela legislação sanitária, e outra unidade para as demais classes.

Neste trabalho, procedeu-se inicialmente à classificação dos trabalhadores da empresa segundo seus respectivos setores e subetapas de cada processo produtivo. Na seqüência, fez-se uma descrição e análise crítica dos processos de fabricação de 
cada forma farmacêutica, tendo em vista a identificação e a classificação dos riscos presentes nas diversas etapas de cada processo segundo os critérios da legislação. A identificação dos riscos foi feita através do acompanhamento de cada processo produtivo e pelo julgamento dos componentes da
CIPA quanto aos possíveis riscos do processo à saúde dos trabalhadores, acrescido de depoimentos e respostas informais dos trabalhadores a perguntas do tipo: "O que você acha que faz mal a sua saúde aqui no seu trabalho?", feitas pelos componentes da comissão.

Quadro 1 Produtos fabricados nas linhas de líquidos não antibióticos, gotas e líquidos antibióticos

\begin{tabular}{|c|l|l|}
\hline Processo produtivo & \multicolumn{1}{|c|}{ Produto } & \multicolumn{1}{|c|}{ Classe terapêutica } \\
\hline \multirow{4}{*}{$\begin{array}{c}\text { Líquidos não antibióticos e } \\
\text { gotas (Linhas 1 e 2) }\end{array}$} & Benzoato de Benzila & Escabicida \\
& Dipirona 50\% & Analgésico e antitérmico \\
& Hidróxido de Alumínio 6,2\% & Antiácido \\
& Mebendazol 2\% & Vermífugo \\
& Cloridrato de Metoclopramida & Antiemético \\
& Paracetamol 1\% & Antifúngico \\
& Pirazinamida 3\% & Analgésico e antitérmico \\
& Polivitaminas & Tuberculostático \\
& Sulfato de Salbutamol 0,4\% & Polivitamínico \\
& Sulfato Ferroso & Antiasmático \\
& Zidovudina 1\% & Antianêmico \\
& Cloranfenicol 0,25\% & Anti-retroviral \\
\hline \multirow{3}{*}{ Líquidos antibióticos (Linha 3) } & Estolato de Eritromicina 2,5\% & Antibiótico \\
& Rifampicina 2\% & Antibiótico \\
& Sulfametoxazol+Trimetoprima & Quimioterápico \\
\hline
\end{tabular}

Quadro 2 Produtos fabricados nas linhas de sólidos e sólidos anti-retrovirais

\begin{tabular}{|c|c|c|}
\hline Processo Produtivo & Produto & Classe terapêutica \\
\hline Sólidos (Linha 1) & $\begin{array}{l}\text { Ácido Acetil Salicílico } 500 \text { e } 100 \text { mg } \\
\text { Ácido Ascórbico } 500 \mathrm{mg} \\
\text { Captopril } 25 \mathrm{mg} \\
\text { Carbonato de Cálcio } 500 \mathrm{mg} \\
\text { Cimetidina } 200 \mathrm{mg} \\
\text { Clorpropamida } \\
\text { Dipirona } 500 \mathrm{mg} \\
\text { Furosemida } 40 \mathrm{mg} \\
\text { Glibenclamida } 5 \mathrm{mg} \\
\text { Hidroclorotiazida } 50 \text { e } 25 \mathrm{mg} \\
\text { Isoniazida + Rifampicina (200+300 mg) } \\
\text { Isoniazida } 100 \mathrm{mg} \\
\text { Mebendazol } 100 \mathrm{mg} \\
\text { Metildopa } 500 \mathrm{mg} \\
\text { Metoclopramida Cloridrato } 10 \mathrm{mg} \\
\text { Propranolol } 40 \mathrm{mg} \\
\text { Sulfametoxazol + Trimetoprima }\end{array}$ & $\begin{array}{l}\text { Analgésico e antitérmico } \\
\text { Vitamina } \\
\text { Anti-hipertensivo } \\
\text { Repositor de cálcio } \\
\text { Antiulceroso } \\
\text { Antidiabético } \\
\text { Analgésico e antitérmico } \\
\text { Diurético } \\
\text { Antidiabético } \\
\text { Anti-hipertensivo } \\
\text { Tuberculostático } \\
\text { Tuberculostático } \\
\text { Vermífugo } \\
\text { Anti-hipertensivo } \\
\text { Antiemético } \\
\text { Anti-hipertensivo } \\
\text { Quimioterápico }\end{array}$ \\
\hline $\begin{array}{l}\text { Sólidos anti-retrovirais } \\
\text { (Linha 2) }\end{array}$ & $\begin{array}{l}\text { Didanosina } 100 \text { e } 25 \mathrm{mg} \\
\text { Estavudina } 40 \text { e } 30 \mathrm{mg} \\
\text { Lamivudina } 150 \mathrm{mg} \\
\text { Sulfato de Indinavir } 400 \mathrm{mg} \\
\text { Ritonavir } \\
\text { Zalcitabina } 0,75 \mathrm{mg} \\
\text { Zidovudina } 100 \mathrm{mg} \\
\text { Zidovudina + Lamivudina }(300+150 \mathrm{mg})\end{array}$ & $\begin{array}{l}\text { Anti-retroviral } \\
\text { Anti-retroviral } \\
\text { Anti-retroviral } \\
\text { Anti-retroviral } \\
\text { Anti-retroviral } \\
\text { Anti-retroviral } \\
\text { Anti-retroviral } \\
\text { Anti-retroviral }\end{array}$ \\
\hline
\end{tabular}


As avaliações foram enquadradas segundo os critérios da legislação (Quadro 3) e segundo um grau de intensidade estabelecido na Quadro 4. De posse do compilado destas, traçou-se um perfil da distribuição dos riscos ocupacionais na produção de medicamentos da empresa estudada e a incidência dos riscos nesta população. Ao final, os resultados obtidos foram avaliados frente aos resultados do PCMSO (Programa de Controle Médico e Saúde Ocupacional) da empresa para estabelecer possíveis relações entre as patologias encontradas na população trabalhadora e a presente avaliação de riscos dos ambientes de trabalho.

Quadro 3 Classificação dos riscos (BRASIL, 1994)

\begin{tabular}{|c|c|c|c|c|}
\hline Riscos físicos & Riscos químicos & Riscos biológicos & $\begin{array}{l}\text { Riscos } \\
\text { ergonômicos }\end{array}$ & Riscos de acidentes \\
\hline Ruído & Poeiras & Vírus & Esforço físico intenso & Arranjo físico inadequado \\
\hline Vibrações & Fumos & Bactérias & $\begin{array}{l}\text { Levantamento e transporte } \\
\text { manual de peso }\end{array}$ & Máquinas e equipamentos sem proteção \\
\hline Radiações ionizantes & Névoas & Protozoários & Exigência de postura inadequada & Ferramentas inadequadas ou defeituosas \\
\hline $\begin{array}{l}\text { Radiações não } \\
\text { ionizantes }\end{array}$ & Neblinas & Fungos & Controle rígido de produtividade & Iluminação inadequada \\
\hline Frio & Gases & Parasitas & Imposição de ritmos excessivos & Eletricidade \\
\hline Calor & Vapores & Bacilos & Trabalho em turno e noturno & Probabilidade de incêndio ou explosão \\
\hline Pressões anormais & $\begin{array}{c}\text { Produtos químicos } \\
\text { em geral }\end{array}$ & & Jornada de trabalho prolongada & $\begin{array}{l}\text { Armazenamento } \\
\text { inadequado }\end{array}$ \\
\hline \multirow[t]{2}{*}{ Umidade } & & & Monotonia e repetitividade & Animais peçonhentos \\
\hline & & & $\begin{array}{l}\text { Outras situações causadoras de } \\
\text { estresse físico e/ou psíquico }\end{array}$ & Situações de acidentes em geral \\
\hline
\end{tabular}

Quadro 4 Classificação dos riscos segundo critérios de intensidade

\begin{tabular}{|c|c|c|c|}
\hline Agentes de riscos & Pequeno & Médio & Grande \\
\hline $\begin{array}{c}\text { Físicos, químicose e } \\
\text { biológicos }\end{array}$ & $\begin{array}{l}\text { Quando os agentes existem } \\
\text { no ambiente, mas em } \\
\text { concentração ou intensida- } \\
\text { de tal que a capacidade de } \\
\text { agressão às pessoas possa } \\
\text { ser considerada desprezível. }\end{array}$ & $\begin{array}{l}\text { Quando as condições agressivas dos } \\
\text { agentes estão abaixo dos limites to- } \\
\text { leráveis para as pessoas, mas ainda } \\
\text { causam desconforto - com ou sem } \\
\text { proteção individual ou coletiva. }\end{array}$ & $\begin{array}{l}\text { Quando concentração, intensidade, tempo de } \\
\text { exposição etc. estão acima dos limites considera- } \\
\text { dos toleráveis pelo organismo humano e não há } \\
\text { proteção individual ou coletiva eficiente. } \\
\text { Quando não existem dados precisos sobre con- } \\
\text { centração, intensidade, tempo de exposição etc. } \\
\text { e, comprovadamente, os agentes estejam afetan- } \\
\text { do a saúde do trabalhador, mesmo que existam } \\
\text { meios de proteção individual e coletiva. }\end{array}$ \\
\hline Ergonômicos & $\begin{array}{c}\text { Podem ser considerados } \\
\text { trabalhos que cansam, com } \\
\text { pouca probabilidade de } \\
\text { afetar a pessoa. }\end{array}$ & $\begin{array}{c}\text { Podem ser consideradas as situa- } \\
\text { ções citadas no item seguinte, } \\
\text { quando ocasionais. }\end{array}$ & $\begin{array}{c}\text { Quando for flagrante: } \\
\text { - trabalho permanente e excessivamente pesado; } \\
\text { - postura totalmente em desacordo com a posição } \\
\text { e os movimentos normais do corpo em longos } \\
\text { períodos; } \\
\text { - jornada de trabalho com muitas horas extras; } \\
\text { - serviços com movimentos rápidos e repetitivos } \\
\text { por longos períodos. }\end{array}$ \\
\hline $\begin{array}{l}\text { De acidentes } \\
\text { (mecânicos) }\end{array}$ & $\begin{array}{l}\text { Podem ser considerados os } \\
\text { trabalhos que não aproxi- } \\
\text { mam os trabalhadores de } \\
\text { pontos agressivos, como, } \\
\text { por exemplo, em máquinas } \\
\text { automáticas. }\end{array}$ & $\begin{array}{l}\text { Podem ser considerados as caracte- } \\
\text { rísticas dos meios e dos processos e } \\
\text { o trabalho que expõe as pessoas ao } \\
\text { perigo, com pouca probabilidade de } \\
\text { lesões sérias. }\end{array}$ & $\begin{array}{c}\text { Quando forem evidentes casos que podem causar } \\
\text { lesões sérias, como: } \\
\text { - máquinas, equipamentos, plataformas, escadas } \\
\text { etc. desprovidos dos meios de segurança; } \\
\text { - arranjo físico serem ou estarem de tal forma } \\
\text { a comprometer seriamente a segurança das } \\
\text { pessoas; } \\
\text { - ferramentas manuais comprometerem ou esta- } \\
\text { rem visivelmente comprometendo a segurança } \\
\text { dos usuários; } \\
\text { - armazenamento ou transporte de materiais de } \\
\text { maneira desordenada e visivelmente inseguras }\end{array}$ \\
\hline
\end{tabular}


Os critérios de classificação de riscos foram baseados na Norma Regulamentadora $\mathrm{n}^{\circ} 9$ do Ministério do Trabalho (BRASIL, 1978), que considera riscos ambientais, os riscos físicos, químicos e biológicos. Riscos físicos se referem à exposição a ruídos, vibrações, radiações não ionizantes, bem como os infra-sons e os ultra-sons; os riscos químicos estão relacionados à exposição a substâncias, compostos ou produtos químicos que possam penetrar no organismo através das vias respiratórias, na forma

\section{Resultados e Discussão}

\section{Perfil da população trabalhadora}

A indústria farmacêutica aqui estudada possuía, à época da pesquisa, 596 trabalhadores em seu quadro de funcionários distribuídos em diversas atividades nos setores produtivo e administrativo. Deste quantitativo, apenas $40,7 \%$ pertencem ao quadro de funcionários efetivos, o remanescente (59,3\%) diz respeito aos empregados prestadores de serviços. Tal diferenciação se faz tendo em vista que o acesso ao quadro de funcionários efetivos se dá através de concurso público, uma vez que a empresa estudada é uma empresa pública. Do total de funcionários, 49,3\% são do sexo masculino e 50,7\%, do sexo feminino. A média de tempo de serviço dos funcionários efetivos nos seus postos de trabalho é de 20 anos, enquanto que, para os terceirizados, este tempo é de 4,3 anos. A Tabela 2 mostra de poeiras, fumos, névoas, neblinas, gases e vapores, ou que, pela natureza da atividade ou exposição, possam ter contato ou ser absorvidos pelo organismo através da pele ou por ingestão; já os riscos biológicos constituem-se devido à exposição a bactérias, fungos, bacilos, parasitas, protozoários, vírus etc. Neste trabalho, foram considerados também os riscos ergonômicos e os riscos de acidentes como previsto nos procedimentos regulamentares para elaboração do Mapa de Riscos (BRASIL, 1994).

uma distribuição da lotação dos trabalhadores segundo o setor em que atuam. Desta, percebe-se que $44,3 \%$ dos trabalhadores estão lotados em áreas administrativas (administração e serviços gerais), enquanto que 55,7\% estão lotados em áreas fabris de produção de medicamentos ou de apoio a esta. Dos setores fabris, o que detém um maior número de trabalhadores é o setor de sólidos $(17,1 \%)$, seguido da produção de líquidos não antibióticos e gotas (10,4\%). Destacam-se ainda os setores auxiliares à produção, como o Controle de Qualidade, Pesquisa e Desenvolvimento (P\&D), utilidades, no qual estão contempladas as gerações de água purificada grau farmacêutico, o vapor através de caldeiras a óleo BPF, o ar comprimido e os sistemas de HVAC (climatização das áreas), que representam 17,6\% dos trabalhadores $(n=105)$ da empresa.

Tabela 2 Distribuição dos trabalhadores segundo o setor em que atuam

\begin{tabular}{lcc}
\hline \multicolumn{1}{c}{ Setor } & $n^{*}$ & $\%$ \\
\hline Almoxarifados de insumos e produto acabado & 34 & 5,7 \\
Sólidos & 102 & 17,1 \\
Sólidos anti-retrovirais & 30 & 5 \\
Líquidos não antibióticos e gotas & 62 & 10,4 \\
Líquidos antibióticos & 20 & 3,4 \\
Controle de qualidade, pesquisa e desenvolvimento (P\&D) & 43 & 7,2 \\
Utilidades (água, vapor, ar comprimido, ar condicionado), engenharia e manutenção & 28 & 4,7 \\
Serviços gerais (refeitório, limpeza, conservação etc.) & 84 & 14,1 \\
Administração & 193 & 32,4 \\
Total & 596 & 100 \\
\hline
\end{tabular}

* número de trabalhadores.

\section{Processos de fabricação de medicamentos}

Os processos de fabricação de medicamentos são escolhidos basicamente em função da forma farmacêutica que se dese- ja obter. As formas farmacêuticas sólidas, que incluem comprimidos, cápsulas e pós, são as formas mais extensamente utilizadas. Já as formas farmacêuticas líquidas, 
que incluem xaropes (soluções concentradas de açúcar), soluções e suspensões, são preparadas para administração a crianças ou a pessoas com dificuldade de engolir comprimidos ou cápsulas e são preparadas utilizando um veículo, que muito comumente é água, no qual as substâncias ativas podem estar dissolvidas ou em suspensão.

Os comprimidos são concebidos, normalmente, contendo na sua composição, além da substância ativa, outras substâncias, não ativas, chamadas de excipientes, responsáveis por assegurar que o medicamento possua peso, volume e consistência necessários para a correta administração do princípio ativo. Três métodos básicos são utilizados para a preparação de comprimidos: granulação úmida, granulação a seco e compressão direta.

No método de granulação úmida, o processo envolve as seguintes etapas básicas: 1) pesagem e mistura dos componentes; 2) preparo da granulação úmida; 3) formação de grânulos pela passagem de massa úmida em tela; 4) secagem; 5) calibração do grânulo seco; 6) mistura de lubrificante; 7) compressão. Na pesagem e na mistura, o princípio ativo, o diluente e o desintegrante presentes na formulação são pesados e misturados normalmente num misturador tipo "V". Para que a mistura de pós flua uniforme e livremente, é necessário converter a mistura de pó para grânulos na etapa de granulação. Isso é obtido adicionando-se um aglutinante líquido à mistura de pó, passando a massa úmida através de um tamis do tamanho desejado, secando o granulado e passando novamente por um segundo tamis de malha menor para reduzir ainda mais o tamanho dos grânulos, etapa conhecida como calibração. Depois da calibração, acrescenta-se um lubrificante seco que pode ser pulverizado sobre o granulado ou misturando num misturador de pó adequado. Na seqüência, o granulado, já lubrificado, alimenta as máquinas de compressão. Nestas, o granulado é pressionado no interior de uma matriz de aço através do movimento de dois punções de aço, um inferior e outro superior. Cada máquina possui um número variável de punções em função de sua capacidade. Após a compressão, os comprimidos podem receber um revestimento da sua superfície e permanecem em quarentena aguardando liberação pelo controle de qualidade. $\mathrm{Na}$ seqüência, recebem a embalagem primária, normalmente blister, que é composto de uma camada de PVC e alumínio ou laminados de alumínio.
O método de granulação a seco é especialmente aplicável a materiais que não podem ser preparados por granulação úmida devido ao fato de se degradarem com a umidade ou com as elevadas temperaturas necessárias para a secagem. Neste método, o grânulo não é formado por umedecimento ou adição de aglutinantes à mistura em pó, mas sim por compactação na forma de grandes comprimidos e subseqüente aglomeração e redução a grânulos menores.

Algumas substâncias químicas granuladas possuem propriedades de coesão que possibilitam que sejam compactadas diretamente, sem necessidade de granulação úmida ou seca. Porém, o número de substâncias ativas que podem ser transformadas em comprimidos sem uma granulação prévia é muito pequeno. O uso de excipientes especiais proporciona a certas formulações as condições necessárias para compressão direta.

As cápsulas utilizam um invólucro de gelatina que carreia no seu interior a mistura de pós ou grânulos formados, onde está a substância ativa por intermédio de máquinas conhecidas como encapsuladeiras.

Da mesma forma que os comprimidos, os medicamentos líquidos são preparados, tendo em sua formulação não só uma substância ativa, mas também conservantes, modificadores de sabor, de cor, agente suspensor, modificadores de viscosidade etc. São preparados em tanques onde as substâncias da formulação, previamente pesadas, são adicionadas aos referidos tanques sob agitação na presença de um veículo que pode ser a água ou outro adequado, proporcionando solubilização ou suspensão dos componentes.

Como já relatado, as indústrias farmacêuticas são projetadas por forma farmacêutica; entretanto, são quase sempre concebidas para fabricação de múltiplos produtos utilizando os mesmos equipamentos de processo. Esta multiplicidade de produtos, de diversas classes terapêuticas, requer a execução de eficientes processos de sanitização e limpeza entre um produto e o subseqüente, tendo em vista a minimização de contaminação cruzada, isto é, a contaminação de um produto por resíduos de princípios ativos, de agentes sanitizantes ou de contaminação microbiana originados no processo de limpeza ou remanescentes do produto fabricado anteriormente. A legislação sanitária, visando à minimização 
de possíveis contaminações cruzadas com substâncias conhecidas como altamente ativas ou altamente sensibilizantes, restringe a fabricação de medicamentos que possuam tais substâncias na sua formulação na mesma área ou utilizando os mesmos equipamentos que outros medicamentos de outras classes terapêuticas. Dentre essas classes de substâncias altamente sensibilizantes, estão os hormônios, os citostáticos, os antibióticos cefalosporínicos, os antibióticos penicilânicos e os antibióticos não beta-lactâmicos. Tais restrições passaram a determinar a disponibilização de proteções especiais para os trabalhadores destas áreas, como, por exemplo, o uso de escafandros como equipamento de proteção individual em todas as etapas do processo produtivo. Este é o caso da fabricação dos medicamentos anti-retrovirais, que, mesmo sem serem considerados como substâncias sensibilizantes por se tratarem de drogas relativamente novas, ainda não exaustivamente estudadas dos pontos de vista toxicológico e ocupacional, foram incluídos nessa lista, promovendo indistintamente a proteção de corpo inteiro dos trabalhadores e minimizando o contato dos mesmos com estes fármacos.

\section{Riscos do processo}

Para cada processo produtivo e suas respectivas etapas foi realizada uma descrição das atividades desenvolvidas e identificados os agentes de riscos detectados, bem como verificado o número de trabalhadores expostos a cada um desses riscos. Os Quadros 5, 6 e 7 resumem todo o levantamento, inclusive das áreas auxiliares e administrativas.

Quadro 5 Processo de fabricação de formas farmacêuticas líquidas (soluções, xaropes, suspensões) e seus riscos

\begin{tabular}{|c|c|c|}
\hline Etapa do processo & Descrição das atividades & Riscos envolvidos \\
\hline $\begin{array}{l}\text { 1. Movimentação de } \\
\text { insumos }\end{array}$ & $\begin{array}{l}\text { Recebimento, conferência, armazenamento } \\
\text { provisórios até que tenham sua qualidade } \\
\text { atestada (quarentena). }\end{array}$ & $\begin{array}{l}\text { Ergonômicos: resultantes de temperaturas desconfortáveis, } \\
\text { esforço físico, mobiliários inadequados, iluminação e arran- } \\
\text { jo físico deficientes. }\end{array}$ \\
\hline $\begin{array}{l}\text { 2. Análise de qualidade } \\
\text { dos insumos }\end{array}$ & $\begin{array}{l}\text { Todas as matérias-primas e os materiais de } \\
\text { embalagem são analisados para verificação } \\
\text { das suas características de qualidade. }\end{array}$ & $\begin{array}{l}\text { Químicos: resultantes da amostragem de matérias-primas } \\
\text { bem como das análises físico-química e microbiológica } \\
\text { destes insumos. } \\
\text { Biológicos: trabalho em ambientes climatizados; possível } \\
\text { proliferação de microorganismos. } \\
\text { Ergonômicos: mobiliário inadequado. }\end{array}$ \\
\hline $\begin{array}{l}\text { 3. Armazenamento de } \\
\text { insumos liberados }\end{array}$ & $\begin{array}{l}\text { Todos os insumos aprovados são armazena- } \\
\text { dos respeitando condições específicas. }\end{array}$ & $\begin{array}{l}\text { Ergonômicos: resultantes de temperaturas desconfortáveis, } \\
\text { esforço físico, mobiliários inadequados, iluminação e arran- } \\
\text { jo físico deficientes. }\end{array}$ \\
\hline $\begin{array}{l}\text { 4. Pesagem e } \\
\text { fracionamento dos } \\
\text { insumos }\end{array}$ & $\begin{array}{l}\text { Fracionamento e pesagem de produtos quími- } \\
\text { cos e farmoquímicos; separação de insumos } \\
\text { de materiais de embalagem requeridos para } \\
\text { uma determinada produção. }\end{array}$ & $\begin{array}{l}\text { Químicos: resultantes do fracionamento e da pesagem de } \\
\text { produtos químicos e farmoquímicos. } \\
\text { Ergonômicos: resultantes de iluminação e arranjo físico } \\
\text { deficientes. }\end{array}$ \\
\hline 5. Liberação de linhas & $\begin{array}{l}\text { Todas as áreas, salas, equipamentos, recipien- } \\
\text { tes e utensílios são limpos e sanitizados antes } \\
\text { da manipulação. }\end{array}$ & $\begin{array}{l}\text { Químicos: resultantes do manuseio dos produtos químicos } \\
\text { sanitizantes. } \\
\text { Biológicos: trabalho em ambientes climatizados; possível } \\
\text { proliferação de microorganismos. }\end{array}$ \\
\hline 6. Manipulação & $\begin{array}{l}\text { Conferências das matérias-primas quanto } \\
\text { ao tipo e ao peso requeridos na formulação; } \\
\text { preparo do medicamento propriamente dito, } \\
\text { isto é, mistura de pós, diluentes, corantes, } \\
\text { essências e conservantes do produto. }\end{array}$ & $\begin{array}{l}\text { Químicos: resultantes do manuseio das matérias-primas da } \\
\text { formulação do medicamento. } \\
\text { Físicos: ruídos provenientes dos equipamentos de processo } \\
\text { (motores, bombas e agitadores). } \\
\text { Biológicos: trabalho em ambientes climatizados; possível } \\
\text { proliferação de microorganismos. } \\
\text { Ergonômicos: esforço físico, manuseio de cargas. }\end{array}$ \\
\hline $\begin{array}{l}\text { 7. Análise de produtos } \\
\text { intermediários }\end{array}$ & $\begin{array}{l}\text { O produto manipulado é analisado pelo } \\
\text { controle da qualidade para verificação da } \\
\text { qualidade. }\end{array}$ & $\begin{array}{l}\text { Químicos: resultantes das análises físico-químicas dos pro- } \\
\text { dutos intermediários. } \\
\text { Biológicos: trabalho em ambientes climatizados; possível } \\
\text { proliferação de microorganismos. } \\
\text { Ergonômicos: mobiliários inadequados. }\end{array}$ \\
\hline
\end{tabular}


(...) Quadro 5 Processo de fabricação de formas farmacêuticas líquidas (soluções, xaropes, suspensões) e seus riscos

\begin{tabular}{|c|c|c|}
\hline Etapa do processo & Descrição das atividades & Riscos envolvidos \\
\hline 8. Envase & $\begin{array}{l}\text { O produto intermediário aprovado pelo } \\
\text { controle de qualidade é transferido para fras- } \\
\text { cos de vidro ou de polietileno num volume } \\
\text { específico. }\end{array}$ & $\begin{array}{l}\text { Físicos: ruídos provenientes do atrito de frascos de vidro, } \\
\text { tampas, copinhos dosadores e do próprio equipamento de } \\
\text { envase. } \\
\text { Biológicos: trabalho em ambientes climatizados; possível } \\
\text { proliferação de microorganismos. } \\
\text { Ergonômicos: mobiliários inadequados. }\end{array}$ \\
\hline 9. Rotulagem & $\begin{array}{l}\text { Os frascos cheios com o medicamento } \\
\text { recebem um rótulo com as informações do } \\
\text { medicamento. }\end{array}$ & $\begin{array}{l}\text { Físicos: ruídos provenientes do atrito de frascos de vidro e } \\
\text { do equipamento de rotulagem. } \\
\text { Biológicos: trabalho em ambientes climatizados; possível } \\
\text { proliferação de microorganismos. } \\
\text { Ergonômicos: mobiliários inadequados. }\end{array}$ \\
\hline 10. Embalagem & $\begin{array}{l}\text { Os frascos rotulados são acondicionados } \\
\text { manualmente em caixas de papelão ondulado } \\
\text { com múltiplas unidades, as quais recebem um } \\
\text { rótulo e as respectivas bulas dos produtos. }\end{array}$ & $\begin{array}{l}\text { Biológicos: trabalho em ambientes climatizados; possível } \\
\text { proliferação de microorganismos. } \\
\text { Ergonômicos: esforço físico na movimentação de caixas do } \\
\text { produto acabado; mobiliários inadequados. }\end{array}$ \\
\hline $\begin{array}{l}\text { 11. Análise do produto } \\
\text { acabado }\end{array}$ & $\begin{array}{l}\text { Antes de serem distribuídos, os medicamen- } \\
\text { tos são novamente analisados pelo controle } \\
\text { de qualidade para verificação de todas as } \\
\text { informações técnicas pertinentes ao produto. }\end{array}$ & $\begin{array}{l}\text { Químicos: resultantes das análises físico-químicas dos pro- } \\
\text { dutos intermediários. } \\
\text { Biológicos: trabalho em ambientes climatizados; possível } \\
\text { proliferação de microorganismos. } \\
\text { Ergonômicos: mobiliários inadequados. }\end{array}$ \\
\hline 12. Expedição & $\begin{array}{l}\text { O medicamento embalado, após aprovação } \\
\text { do controle de qualidade, é enviado ao almo- } \\
\text { xarifado para distribuição. }\end{array}$ & $\begin{array}{l}\text { Ergonômicos: esforço físico por movimentação de caixas do } \\
\text { produto acabado. }\end{array}$ \\
\hline
\end{tabular}

Quadro 6 Processo de fabricação de formas farmacêuticas sólidas (comprimidos, comprimidos revestidos, cápsulas, pós) e seus riscos

\begin{tabular}{|c|c|c|}
\hline Etapa do processo & Descrição das atividades & Riscos envolvidos \\
\hline $\begin{array}{l}\text { 1. Movimentação de } \\
\text { insumos }\end{array}$ & $\begin{array}{l}\text { Recebimento, conferência, armazenamento } \\
\text { provisórios até que tenham sua qualidade } \\
\text { atestada (quarentena). }\end{array}$ & $\begin{array}{l}\text { Ergonômicos: resultantes de temperaturas desconfortáveis, } \\
\text { esforço físico, mobiliários inadequados, iluminação e arran- } \\
\text { jo físico deficientes. }\end{array}$ \\
\hline $\begin{array}{l}\text { 2. Análise de qualidade } \\
\text { dos insumos }\end{array}$ & $\begin{array}{l}\text { Todas as matérias-primas e os materiais de } \\
\text { embalagem são analisados para verificação } \\
\text { das suas características de qualidade. }\end{array}$ & $\begin{array}{l}\text { Químicos: resultantes da amostragem de matérias-primas } \\
\text { bem como das análises físico-químicas e microbiológicas } \\
\text { destes insumos. }\end{array}$ \\
\hline $\begin{array}{l}\text { 3. Armazenamento de } \\
\text { insumos liberados }\end{array}$ & $\begin{array}{l}\text { Todos os insumos aprovados são armazena- } \\
\text { dos respeitando condições específicas. }\end{array}$ & $\begin{array}{l}\text { Ergonômicos: resultantes de temperaturas desconfortáveis, } \\
\text { esforço físico, mobiliários inadequados, iluminação e arran- } \\
\text { jo físico deficientes. }\end{array}$ \\
\hline $\begin{array}{l}\text { 4. Pesagem e fraciona- } \\
\text { mento dos insumos }\end{array}$ & $\begin{array}{l}\text { Fracionamento e pesagem de produtos } \\
\text { químicos e farmoquímicos; separação de } \\
\text { insumos de materiais de embalagem requeri- } \\
\text { dos para uma determinada produção. }\end{array}$ & $\begin{array}{l}\text { Químicos: resultantes do fracionamento e da pesagem de } \\
\text { produtos químicos e farmoquímicos. } \\
\text { Ergonômicos: resultantes de iluminação e arranjo físico } \\
\text { deficientes. }\end{array}$ \\
\hline 5. Liberação de linhas & $\begin{array}{l}\text { Todas as áreas, salas, equipamentos, reci- } \\
\text { pientes e utensílios são limpos e sanitizados } \\
\text { antes da manipulação; conferência das } \\
\text { matérias-primas quanto ao tipo e ao peso } \\
\text { requeridos na formulação. }\end{array}$ & $\begin{array}{l}\text { Químicos: resultantes do manuseio de produtos químicos } \\
\text { sanitizantes. } \\
\text { Biológicos: trabalho em ambientes climatizados; possível } \\
\text { proliferação de microorganismos. }\end{array}$ \\
\hline 6. Tamização e mistura & $\begin{array}{l}\text { Ajuste da granulometria dos pós utilizando } \\
\text { um jogo de tamiz; mistura de pós, principais } \\
\text { componentes da formulação. }\end{array}$ & $\begin{array}{l}\text { Químicos: resultante do manuseio das matérias-primas. } \\
\text { Físicos: ruídos provenientes dos equipamentos. }\end{array}$ \\
\hline
\end{tabular}


(...) Quadro 6 Processo de fabricação de formas farmacêuticas sólidas (comprimidos, comprimidos revestidos, cápsulas, pós) e seus riscos

\begin{tabular}{|c|c|c|}
\hline Etapa do processo & Descrição das atividades & Riscos envolvidos \\
\hline $\begin{array}{l}\text { 7. Granulação / seca- } \\
\text { gem / normalização } \\
\text { (calibração) }\end{array}$ & $\begin{array}{l}\text { Etapa utilizada para processos que não } \\
\text { utilizam compressão direta quando se deseja } \\
\text { obter grânulos com a finalidade de promo- } \\
\text { ver a adesão entre as partículas durante a } \\
\text { compressão / uso de estufas para retirada do } \\
\text { excesso de umidade do granulado / unifor- } \\
\text { mização do tamanho dos grânulos através de } \\
\text { nova tamização. }\end{array}$ & $\begin{array}{l}\text { Químicos: resultantes do manuseio da mistura de pós. } \\
\text { Físicos: ruídos provenientes dos equipamentos de granula- } \\
\text { ção e calibração. } \\
\text { Biológicos: trabalho em ambientes climatizados; possível } \\
\text { proliferação de microorganismos. } \\
\text { Ergonômicos: esforço físico e mobiliários inadequados. }\end{array}$ \\
\hline $\begin{array}{l}\text { 8. Análise de produtos } \\
\text { a granel (pós) }\end{array}$ & $\begin{array}{l}\text { O produto manipulado é analisado para } \\
\text { verificação da qualidade. }\end{array}$ & $\begin{array}{l}\text { Químicos: resultantes das análises físico-químicas dos pro- } \\
\text { dutos intermediários. } \\
\text { Biológicos: trabalho em ambientes climatizados; possível } \\
\text { proliferação de microorganismos. } \\
\text { Ergonômicos: mobiliários inadequados. }\end{array}$ \\
\hline 9. Compressão & $\begin{array}{l}\text { Compactação dos pós adquirindo a forma de } \\
\text { comprimido. }\end{array}$ & $\begin{array}{l}\text { Químicos: resultantes do manuseio das matérias-primas da } \\
\text { formulação do medicamento. } \\
\text { Físicos: ruídos provenientes do equipamento de compres- } \\
\text { são. } \\
\text { Biológicos: trabalho em ambientes climatizados; possível } \\
\text { proliferação de microorganismos. } \\
\text { Ergonômicos: esforço físico e mobiliários inadequados. }\end{array}$ \\
\hline $\begin{array}{l}\text { 10. Análise de produtos } \\
\text { intermediários }\end{array}$ & $\begin{array}{l}\text { O produto manipulado é analisado para } \\
\text { verificação da qualidade. }\end{array}$ & $\begin{array}{l}\text { Químicos: resultantes das análises físico-químicas dos pro- } \\
\text { dutos intermediários. } \\
\text { Biológicos: trabalho em ambientes climatizados; possível } \\
\text { proliferação de microorganismos. } \\
\text { Ergonômicos: mobiliários inadequados. }\end{array}$ \\
\hline 11. Revestimento & $\begin{array}{l}\text { Alguns tipos de comprimidos necessitam } \\
\text { receber aplicação de uma fina camada de po- } \\
\text { límero, formando uma película que o reveste. }\end{array}$ & $\begin{array}{l}\text { Químicos: resultantes do preparo de soluções de revesti- } \\
\text { mentos. } \\
\text { Físicos: ruídos provenientes do equipamento de revestimen- } \\
\text { to. } \\
\text { Biológicos: trabalho em ambientes climatizados; possível } \\
\text { proliferação de microorganismos. } \\
\text { Ergonômicos: esforço físico e mobiliários inadequados. }\end{array}$ \\
\hline $\begin{array}{l}\text { 12. Embalagem primá- } \\
\text { ria (emblistamento, } \\
\text { envelopamento ou } \\
\text { envase) }\end{array}$ & $\begin{array}{l}\text { Embalagem dos comprimidos em blister, } \\
\text { envelopes ou frascos, onde os comprimidos } \\
\text { ficam entre uma camada de PVC e uma cama- } \\
\text { da de alumínio, duas camadas de alumínio ou } \\
\text { frascos de polietileno. }\end{array}$ & $\begin{array}{l}\text { Químicos: resultantes do pó gerado no atrito dos comprimi- } \\
\text { dos com os equipamentos. } \\
\text { Físicos: ruídos provenientes das máquinas envelopadeiras } \\
\text { ou emblistadeiras. } \\
\text { Biológicos: trabalho em ambientes climatizados; possível } \\
\text { proliferação de microorganismos. } \\
\text { Ergonômicos: esforço físico e mobiliários inadequados. }\end{array}$ \\
\hline $\begin{array}{l}\text { 13. Embalagem } \\
\text { secundária / terciária / } \\
\text { rotulagem }\end{array}$ & $\begin{array}{l}\text { Acondicionamento de múltiplas unidades de } \\
\text { blisters ou envelopes em caixas de papelão } \\
\text { ou cartolina (secundária) e estas em caixas } \\
\text { de papelão ondulado (terciária). As caixas } \\
\text { recebem um rótulo com as informações do } \\
\text { medicamento além de suas respectivas bulas. }\end{array}$ & $\begin{array}{l}\text { Físicos: ruídos provenientes das emblistadeiras. } \\
\text { Biológicos: trabalho em ambientes climatizados; possível } \\
\text { proliferação de microorganismos. } \\
\text { Ergonômicos: esforço físico, mobiliários inadequados e } \\
\text { monotonia. }\end{array}$ \\
\hline $\begin{array}{l}\text { 14. Análise do produto } \\
\text { acabado }\end{array}$ & $\begin{array}{l}\text { Antes de serem distribuídos, os medicamen- } \\
\text { tos são novamente analisados pelo controle } \\
\text { de qualidade para verificação de todas as in- } \\
\text { formações técnicas pertinentes ao produto. }\end{array}$ & $\begin{array}{l}\text { Químicos: resultantes das análises físico-químicas dos pro- } \\
\text { dutos acabados. } \\
\text { Biológicos: trabalho em ambientes climatizados; possível } \\
\text { proliferação de microorganismos. } \\
\text { Ergonômicos: mobiliários inadequados. }\end{array}$ \\
\hline 15. Expedição & $\begin{array}{l}\text { Os medicamentos embalados, após aprova- } \\
\text { ção do controle de qualidade, são enviados } \\
\text { ao almoxarifado para distribuição. }\end{array}$ & $\begin{array}{l}\text { Ergonômicos: esforço físico por movimentação das caixas } \\
\text { dos produtos acabados. }\end{array}$ \\
\hline
\end{tabular}


Quadro 7 Processos auxiliares da fabricação de medicamentos e seus riscos

\begin{tabular}{|c|c|c|}
\hline Etapa do processo & Descrição das atividades & Riscos envolvidos \\
\hline 1. Utilidades & $\begin{array}{l}\text { Produção de água purificada, ar comprimido, } \\
\text { ar condicionado e vapor d'água, oficinas de } \\
\text { manutenção elétrica e mecânica. }\end{array}$ & $\begin{array}{l}\text { Químicos: resultantes do manuseio de produtos químicos de } \\
\text { tratamento de água e geração de vapor. } \\
\text { Físicos: ruídos provenientes de caldeiras, bombas e compres- } \\
\text { sores, além de temperaturas elevadas na geração de vapor. } \\
\text { Ergonômicos: esforço físico e mobiliários inadequados. }\end{array}$ \\
\hline $\begin{array}{l}\text { 2. Pesquisa e } \\
\text { Desenvolvimento } \\
(P \& D)\end{array}$ & $\begin{array}{l}\text { Fabricação de lotes de medicamentos em } \\
\text { escala piloto e semi-industrial para estu- } \\
\text { do; desenvolvimento de novos produtos e } \\
\text { otimização de formulações; execução de } \\
\text { análises físico-químicas em matérias-primas, } \\
\text { produtos acabados e em processos de medi- } \\
\text { camentos em estudo. }\end{array}$ & $\begin{array}{l}\text { Químicos: resultantes do manuseio de produtos químicos de } \\
\text { análises físico-químicas e da manipulação de matérias-pri- } \\
\text { mas no preparo de lotes pilotos de medicamentos. } \\
\text { Físicos: ruídos provenientes de equipamentos de bancada e } \\
\text { escala semi-industrial. } \\
\text { Ergonômicos: esforço físico e mobiliários inadequados. }\end{array}$ \\
\hline 3. Administração & $\begin{array}{l}\text { Atividades administrativas (licitações, } \\
\text { jurídico, financeiro, contabilidade, recursos } \\
\text { humanos, informática, suprimentos, planeja- } \\
\text { mento, vendas, BPF). }\end{array}$ & $\begin{array}{l}\text { Ergonômicos: esforços repetitivos, mobiliários inadequados } \\
\text { e iluminação deficiente. }\end{array}$ \\
\hline 4. Serviços gerais & $\begin{array}{l}\text { Vigilância, refeitório, telefonistas, transpor- } \\
\text { tes, carpintaria, pintura, limpeza e conser- } \\
\text { vação. }\end{array}$ & $\begin{array}{l}\text { Químicos: resultantes do manuseio de produtos químicos de } \\
\text { limpeza e conservação, tintas e solventes para pintura. } \\
\text { Físicos: ruídos para telefonistas; ruído e calor na carpintaria; } \\
\text { calor no refeitório. } \\
\text { Biológicos: limpeza e conservação de sanitários. } \\
\text { Ergonômicos: esforço físico, mobiliários inadequados e } \\
\text { iluminação deficiente. }\end{array}$ \\
\hline
\end{tabular}

A Tabela 3 e a Figura 1 mostram o resultado da distribuição do número de trabalhadores em função da exposição ao risco e em função dos subprocessos da fabricação de medicamentos. Observa-se que há uma prevalência de exposição a riscos ergonô- micos, isto é, 95\% dos trabalhadores estão expostos a riscos desta natureza. Tal exposição no processo produtivo é resultante de esforços físicos diversos e habilidades repetitivas aliados a exigências de postura inadequada, situação mais comum ao longo de toda a empresa.

Tabela 3 Distribuição dos trabalhadores segundo a exposição ao risco

\begin{tabular}{|c|c|c|c|c|c|}
\hline Setor & Riscos químicos & Riscos físicos & Riscos biológicos & Riscos de acidentes & Riscos ergonômicos \\
\hline Almoxarifados de insumos e PA & 4 & 10 & --- & 34 & 32 \\
\hline Sólidos & 63 & 95 & 100 & 56 & 102 \\
\hline Sólidos anti-retrovirais & 15 & 18 & 29 & 10 & 30 \\
\hline Líquidos não antibióticos e gotas & 8 & 25 & 40 & 10 & 45 \\
\hline Líquidos antibióticos & 5 & 10 & 16 & 6 & 17 \\
\hline Controle de qualidade, $P \& D$ & 40 & 31 & 39 & 11 & 43 \\
\hline Utilidades, engenharia e manutenção & 22 & 23 & --- & 27 & 28 \\
\hline Serviços gerais & 33 & 27 & 29 & 84 & 81 \\
\hline Administração & 7 & 7 & --- & 188 & 188 \\
\hline Total & 197 & 246 & 253 & 426 & 566 \\
\hline \% da população total & 33 & 41,3 & 42,4 & 71,5 & 95 \\
\hline
\end{tabular}




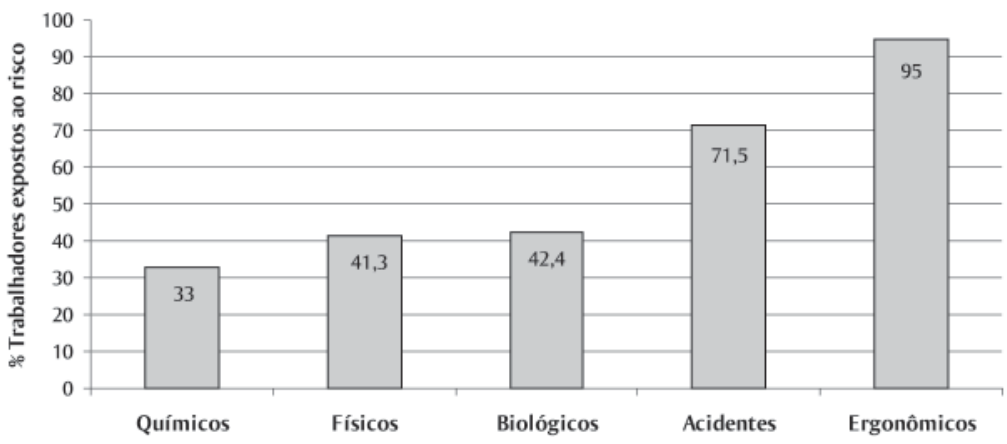

Figura 1 Distribuição dos trabalhadores segundo a exposição ao risco

Na escala de prevalência dos riscos, aparece em seguida o risco de acidentes, sendo o principal potencial agente causador os níveis de iluminação que estiveram, na sua grande maioria, inadequados para cada atividade desenvolvida.

Os riscos biológicos vêm em seguida, atingindo um percentual de $42,4 \%$ da população trabalhadora, e foram identificados como presentes, principalmente, em função dos trabalhadores das áreas fabris desenvolverem atividades em ambientes climatizados, cujo controle possibilita a manutenção dos parâmetros de temperatura, umidade, níveis de contaminação microbiana, que em casos de desvios podem levar ao desenvolvimento de fungos, bolores e microorganismos patogênicos, poluentes e ao conseqüente aparecimento de problemas de saúde motivados por estes fatores. Vale lembrar que, segundo a Organização Mundial de Saúde (OMS), mais da metade dos locais fechados, como empresas, escolas, cinemas, residências e até hospitais, tem ar de má qualidade, sendo este baixo padrão de qualidade causado principalmente por má higienização dos sistemas de ar condicionado e pela falta de controle periódico sobre as possíveis fontes de contaminação. Acredita-se que as constantes exposições a ambientes climatizados sem controles adequados podem gerar supressão do sistema imunológico, processos alérgicos e sintomas variados - cefaléia, dor articular, irritação ocular e nas vias respiratórias, tosse seca, dermatite, fadiga, sonolência, dificuldade de con- centração e sensibilidade a odores e outras doenças (CAASI, 2003).

Por fim, surgem os riscos físicos e químicos que atingem $41,3 \%$ e $33 \%$ dos trabalhadores respectivamente. Os riscos físicos são oriundos principalmente dos ruídos de máquinas e equipamentos e os riscos químicos são resultantes do contato com uma grande variedade de produtos químicos, substâncias ativas (fármacos), excipientes de formulação, solventes, ácidos, bases etc. apresentados muitas vezes na forma de pós. E é na forma de partículas em suspensão (poeiras) que a exposição dos trabalhadores mais se apresenta.

Fica clara a diversidade dos riscos nos ambientes de trabalho da indústria de medicamentos. Convém também observar que tais riscos se apresentam de formas distintas nos diversos processos produtivos e em cada uma das subetapas destes processos, tendo em vista que os riscos se manifestam com maior ou menor intensidade.

Isso posto, fez-se necessária a classificação dos riscos segundo critérios de intensidade nos quais se apresentam. Os riscos foram classificados segundo a intensidade (pequeno, médio e grande) e os critérios que os diferenciam estão mostrados no Quadro 4. Escolhido o critério, fez-se uma classificação de todos os riscos ambientais já identificados na Tabela 3 segundo os critérios de intensidade. Um compilado dos graus de riscos identificados está mostrado na Tabela 4. 
Tabela 4 Distribuição dos riscos segundo critérios de intensidade

\begin{tabular}{lcccccc}
\hline Intensidade do risco & Riscos químicos & Riscosfísicos & Riscos biológicos & Riscos de acidentes & Riscos ergonômicos & Total \\
\hline Grande & 73 & 4 & ---- & --- & 11 & 88 \\
Médio & 49 & 159 & ---- & 66 & 68 & 342 \\
Pequeno & 75 & 83 & 253 & 253 & 426 & 487 \\
\hline Total & 197 & 246 & & 566 \\
\hline
\end{tabular}

Analisando os dados da Tabela 4, percebe-se que, ao longo de todo o processo produtivo, os 197 trabalhadores estão expostos a riscos químicos de intensidades diferentes: $37 \%$ são de grande intensidade, $25 \%$ de média intensidade e $38 \%$ de pequena intensidade. Para os riscos físicos, os percentuais mudam para $1 \%$ para os riscos de grande intensidade, $65 \%$ para os de média intensidade e $34 \%$ para os de pequena intensidade. Para os riscos biológicos, $100 \%$ destes foram classificados como de pequena intensidade. Quanto aos riscos de acidentes, $85 \%$ foram classificados como de pequena intensidade e 15\% como de média intensidade. Por fim, dos riscos ergonômicos, $2 \%$ foram classificados como de grande intensidade, $12 \%$ como de média e $86 \%$ como de pequena intensidade.

Analisando estes mesmos dados tendo em vista a priorização dos riscos para desenvolvimento de ações preventivas, percebe-se que $83 \%$ dos trabalhadores expostos a riscos de grande intensidade estão expostos a riscos de natureza química, $46,5 \%$ dos trabalhadores expostos a riscos de média intensidade estão expostos aos de natureza física e $68 \%$ dos riscos de pequena intensidade foram relacionados a riscos de acidentes (29\%) ou riscos ergonômicos (39\%). Até aqui, a população estudada foi classificada segundo os riscos a que está exposta. Na seqüência, os riscos identificados foram classificados segundo um grau de intensidade, possibilitando a priorização de ações preventivas. Imprescindível se faz a localização destes riscos no processo de fabricação dos medicamentos. Cada linha da Tabela 5 foi desmembrada segundo a lotação dos trabalhadores no processo produtivo para obtenção deste objetivo. O resultado está mostrado nas Tabelas 5, 6 e 7 , em que $n$ é o número de trabalhadores expostos segundo o grau de intensidade dos riscos.

Tabela 5 Distribuição dos riscos de grande intensidade $(n=88)$

\begin{tabular}{|c|c|c|c|c|c|}
\hline Setor & Riscos químicos & Riscos físicos & Riscos biológicos & Riscos de acidentes & Riscos ergonômicos \\
\hline Almoxarifados de insumos e PA & 2 & & & & 7 \\
\hline Sólidos & 9 & & & & \\
\hline \multicolumn{6}{|l|}{ Sólidos anti-retrovirais } \\
\hline Líquidos não antibióticos e gotas & 7 & & & & 2 \\
\hline Líquidos antibióticos & 4 & & & & 2 \\
\hline Controle de qualidade, $P \& D$ & 37 & & & & \\
\hline Utilidades, engenharia e manutenção & 7 & 4 & & & \\
\hline Serviços gerais & 2 & & & & \\
\hline Administração & 5 & & & & \\
\hline
\end{tabular}


Tabela 6 Distribuição dos riscos de média intensidade $(n=342)$

\begin{tabular}{|c|c|c|c|c|c|}
\hline Setor & Riscos químicos & Riscos físicos & Riscos biológicos & Riscos de acidentes & Riscos ergonômicos \\
\hline Almoxarifados de insumos e PA & 2 & 9 & & 7 & 10 \\
\hline Sólidos & 18 & 66 & & 1 & 19 \\
\hline Sólidos anti-retrovirais & 10 & 11 & & & 4 \\
\hline Líquidos não antibióticos e gotas & & 17 & & & 25 \\
\hline Líquidos antibióticos & & 6 & & & 9 \\
\hline Controle de qualidade, $P \& D$ & 3 & & & 35 & 1 \\
\hline Utilidades, engenharia e manutenção & 14 & 19 & & 23 & \\
\hline Serviços gerais & & 24 & & & \\
\hline Administração & 2 & 7 & & & \\
\hline
\end{tabular}

Tabela 7 Distribuição dos riscos de pequena intensidade $(n=1258)$

\begin{tabular}{|c|c|c|c|c|c|}
\hline Setor & Riscos químicos & Riscos físicos & Riscos biológicos & Riscos de acidentes & Riscos ergonômicos \\
\hline Almoxarifados de insumos e PA & & 3 & & 17 & 5 \\
\hline Sólidos & 33 & 38 & 112 & 50 & 108 \\
\hline Sólidos anti-retrovirais & 4 & 3 & 25 & 9 & 25 \\
\hline Líquidos não antibióticos e gotas & 5 & & 36 & 2 & 10 \\
\hline Líquidos antibióticos & 1 & & 12 & 2 & 4 \\
\hline Controle de qualidade, P\&D & & 31 & 39 & 3 & 45 \\
\hline Utilidades, engenharia e manutenção & 1 & & & & 16 \\
\hline Serviços gerais & 31 & 3 & 29 & 84 & 81 \\
\hline Administração & & 5 & & 193 & 193 \\
\hline
\end{tabular}

A Tabela 5 mostra que os setores de controle de qualidade e a área de produção de formas sólidas são os responsáveis pela exposição do maior número de trabalhadores ao efeito de substâncias químicas. No primeiro, a exposição é resultante da exposição durante o processo de amostragem e de análises físico-química e microbiológica de todos os insumos necessários à fabricação dos medicamentos (matérias-primas e materiais de embalagem), além de produtos em processo (intermediários) e produtos acabados. No segundo, a exposição a poeiras geradas durante as várias etapas do processo de fabricação de comprimidos é a situação mais comum. Eis uma grande característica deste processo: a grande geração de poeiras, as quais tomam importância ainda maior quando se sabe que muitos fármacos possuem concentrações mínimas capazes de ainda provocar alguma resposta terapêutica inferior ao limite de tolerância para poeiras "não classificadas”, como normalmente são.

Já nos riscos de média intensidade, em que prevalecem os riscos físicos, o agente principal que representa este grupo de riscos é o ruído, gerado normalmente pela utilização freqüente de máquinas e equipamentos em grande parte das subetapas do processo de fabricação de formas sólidas.

Nos riscos de pequena intensidade, há um grande número de trabalhadores sob o efeito de riscos biológicos, ergonômicos e de pequenos acidentes. O primeiro predomina nas áreas produtivas e se deve à exposição a ambientes climatizados; o segundo e o terceiro, a posturas inadequadas, monotonia, trabalhos repetitivos, problemas de layout, iluminação inadequada e situações de acidentes em geral bem distribuídos por todos os setores da empresa, inclusive nas áreas administrativas.

Utilizando dados do PCMSO (Programa de Controle Médico e Saúde Ocupacional) da empresa estudada, levantaram-se as principais patologias nos trabalhadores e observou-se que os dados ainda não são suficientes para estabelecer a existência de evidências de nexo causal entre os riscos identificados em cada etapa dos processos e essas doenças. A Tabela 8 resume as principais doenças identificadas nos setores produtivos no ano de 2003. 
Tabela 8 Principais patologias identificadas por setor produtivo, 2003

\begin{tabular}{llc}
\hline \multicolumn{1}{c}{ Setor } & \multicolumn{1}{c}{ Principais doenças } & $n^{*}$ \\
\hline \multirow{3}{*}{ Produção de líquidos } & Doenças do sistema osteomuscular & 3 \\
& Hipertensão & 2 \\
& Doenças do sistema respiratório & 2 \\
& Enxaqueca & 1 \\
& Anemias & 1 \\
& Transtorno depressivo & 1 \\
& Obesidade & 1 \\
\hline \multirow{2}{*}{ Produção de sólidos } & Hipertensão & 4 \\
& Anemias & 1 \\
& Doenças do sistema osteomuscular & 5 \\
& Dermatoses & 1 \\
\hline \multirow{2}{*}{ Controle de qualidade } & Asma não especificada & 1 \\
& Labirintite & 1 \\
\hline
\end{tabular}

* número de trabalhadores.

\section{Conclusão}

Este trabalho teve como objetivo a identificação dos riscos do processo de trabalho de uma indústria farmacêutica produtora de medicamentos. O cenário estudado foi uma grande indústria estatal localizada no nordeste brasileiro e o estudo revelou que a fabricação de medicamentos é desenvolvida sob uma série de riscos físicos, químicos, biológicos e ergonômicos que poderão repercutir na saúde dos trabalhadores ou possibilitar a ocorrência de acidentes de trabalho. A presença desses múltiplos agentes de risco no processo produtivo requer um aperfeiçoamento das técnicas de controle dos mesmos bem como o desenvolvimento de sistemáticas mais apuradas para verificação do nexo causal entre os riscos aqui apontados e as patologias surgentes na população exposta.

\section{Agradecimentos}

Aos trabalhadores do Laboratório Farmacêutico do Estado de Pernambuco S/A (LAFE$\left.P E^{\circledast}\right)$ que no exercício de suas funções possibilitaram a realização deste trabalho e desta pesquisa.

\section{Referências Bibliográficas}

AGIUS, R. M. et al. Occupational asthma in salbutamol process workers. Ocсuppational and Environmental Medicine. v. 51, n. 6, p. 397-399, 1994.

ALENCAR, J. R. B. Saudáveis, mas nem tanto. Revista Proteção. p. 40-41, 1999.

BRASIL. Ministério do Trabalho. Portaria $\mathrm{n}^{\mathrm{o}} 3214$ de 08.06.1978. Normas Regulamentadoras (NR) de Segurança e Medicina do Trabalho, 1978.

BRASIL. Ministério do Trabalho. Portaria $\mathrm{n}^{\mathrm{o}} 25$ de 29.12.1994. Modifica NR-5 e es- tabelece procedimentos para elaboração do mapa de riscos. 1994.

BRASIL. Ministério da Saúde. Agência Nacional de Vigilância Sanitária (ANVISA). Resolução RDC nº 210 de 04.08.2003. Regulamento técnico de boas práticas de fabricação de medicamentos, Diário Oficial da União, p. 24-50, 14 de ago. 2003.

CAASI. Manutenção de sistemas de refrigeração, riscos à saúde e doenças relacionadas às edificações. Disponível em: $\underline{w w w}$. caasi.com.br. Acesso em: 28 nov. 2003. 
CHIDA, T. A study on dose-response relationship of occupational allergy in a pharmaceutical plat. Sangyo Igaku. v. 28, n. 2, p. 77-86, 1986.

CHIDA, T.; \& UEHATA, T. Some experiments on the allergic reaction among workers in pharmaceutical factory. Sangyo Igaku. v. 21, n. 5, p. 422-432, 1979.

DAVIES, R. J.; \& PAPYS, J. Asthma due to inhaled chemical agents - the macrolide antibiotic Spiramycin. Clinical and Allergy. v. 5, n. 1, p. 99-107, 1975.

EKENVALL, L.; \& FORSBECK, M. Contact eczema produced by a beta-adrenergic blocking agent (alprenolol). Contact Dermatitis. v. 4, n. 4, p. 190-194, 1978.

HARRINGTON, J. M.; \& GOLDBLATT, P. Census based mortality study of pharmaceutical industry workers. Br. J. Ind. Med. v. 43, n. 3, p. 206-211, 1986.

HANSSON, E. et al. Pregnancy outcome for women working in laboratories in some of the pharmaceutical industries in Sweden. Scandinavian Journal of Work, Environmental and Health. v. 6, n. 2, p. 131-134, 1980.

LAGIER, F. et al. Occupational asthma in a pharmaceutical worker exposed to penicilamine. Thorax. v. 44, n. 2, p. 157-158, 1989.

LOSADA, E. et al. Occupational asthma caused by alpha-amylase inhalation: clinical and immunologic findings and bronchial response patterns. Journal of Allergy and Clinical Immunology. v. 89, n. 1, p. 118-125, 1992.

MALET, A. et al. Occupational hypersensitivity to spiramycin: report of a case. Allergologia and Immunopathologia. v. 20, n. 3, p. 127-130, 1992.

MALO, J. L., CARTIER, A. Occupational asthma in workers of a pharmaceutical company processing spiramycin. Thorax. v. 43, n. 5, p. 371-377, 1988.

MARTINDALE - The Extra Pharmacopoeia, $31^{\text {th }}$ ed. London: Royal Pharmaceutica Society, 1996. p. 1665.

MELO, M. G. M. Estudo de dermatoses dos trabalhadores de uma indústria farmacêutica. 1999. 87p. Dissertação (Mestrado) - Escola Nacional de Saúde Pública, Fundação Oswaldo Cruz, Rio de Janeiro.
MENON, M. P.; \& DAS, A. K. Tetracycline asthma - a case report. Clinical and Allergy. v. 7, n. 3, p. 285-290, 1977.

MERLER, E.; VILLA, L.; \& LUCCHINI, R. Pathological effects due to antineoplasic drugs in workers engaged in their production, preparation or administration. $\mathrm{Me}$ dicina del Lavoro. v. 87, n. 3, p. 207-221, 1996.

MOSCATO, G. et al. Occupational asthma, rhinitis and urticaria due to piperacilin sodium in a pharmaceutical worker. The European Respiratory Journal. v. 8, n. 3, p. 467-469, 1975.

NAUMANN B. D.; \& SARGENT E. V. Setting occupational exposure limits for pharmaceuticals. Occupational Medicine. v. 12, n. 1, p. 67-80, 1997.

PERRIN, B. et al. Occupational asthma in a pharmaceutical worker exposed to hydralazine. Thorax. v. 45, n. 12, p. 980981, 1990.

PUSHPAVATHI, K. et al. Chromosomal aberrations in lymphocytes of pharmaceutical factory workers. Environmental Research. v. 41, p. 88-90, 1986.

RAMAZZINI, B. As doenças dos trabalhadores. São Paulo: Fundacentro,1992.

REGO, M. A. V. et al. Saúde e trabalho numa indústria farmacêutica. Rev. bras. saúde ocup. v. 79, n. 21, p. 39-47, 1993.

REMBADEL, P.; \& RUDZKI, E. Occupational allergy in the production of drugs. Polski Tygodnik Lekarski. v. 45, n. 4-5, p. 82-84, 1990.

SARGENT, E.; \& KIRK, D. Establishing airborne exposure control limits in the pharmaceutical industry. American Industrial Hygiene Association Journal. v. 49, n. 6, p. 309-313, 1988.

SESSINK, P. J. et al. Biological and a enviromental monitoring of occupational exposure of pharmaceutical plant workers to methotrexate. International Archives of Occupational and Environmental Health. v. 65, n. 6, p. 401-403, 1994.

THOMAS, T. L.; \& DECOUFLE, P. Mortality among workers employed in the pharmaceutical industry: a preliminary investigation. Journal of Occupational Medicine. v. 21, n. 9, p. 619-623, 1979.

TOMEI, F. et al. Liver damage in pharmaceutical industry workers. Archives of Environmental Health. v. 50, n. 4, p. 293-297, 1995. 